\title{
TECNOLOGIAS DIGITAIS como POSSIBILIDADE para COMPREENDER A PRODUÇÃO DE CONHECIMENTO EM MATEMÁTICA
}

\section{DIGITAL TECHNOLOGIES as a POSSIBILITY to UNDERSTAND THE KNOWLEDGE PRODUCTION IN MATHEMATICS}

\author{
Rosa Monteiro Paulo ${ }^{1}$ \\ Ingrid Cordeiro Firme ${ }^{2}$ \\ Cristiano Natal Tonéis ${ }^{3}$
}

\begin{abstract}
Resumo: Neste artigo discutimos o modo pelo qual se pode compreender o sentido das Tecnologias Digitais (TD) e sua potencialidade para a produção de conhecimento em matemática, especificamente no contexto da sala de aula e da formação de professores. Destaca-se que a produção, na perspectiva fenomenológica, é entendida como um movimento dinâmico que acontece no mundo da experiência vivida (BICUDO, 2000), enfatizando que sendo humanos é de onde podemos falar: da realidade mundana (HEIDEGGER, 2005). O mundo, como campo de vivência e possibilidade de o sujeito pensar e se expressar se abre à compreensão e os sentidos e significados vão se articulando nos atos vivenciais. O mundo, sempre compartilhado com os outros (seres e objetos), é o horizonte de possibilidades de ser e de conhecer. Nesse horizonte as TD são objetos intencionais, abertas à percepção e compreensão. São tematizadas e se expõem segundo um modo de dar-se a conhecer.
\end{abstract}

Palavras-chave: Educação Matemática; Fenomenologia; Jogos Digitais; Formação de Professores.

\begin{abstract}
In this article we discuss the way in which one can understand the meaning of Digital Technologies (DT) and its potential for the production of knowledge in mathematics, specifically in the context of the classroom and teacher training. It is emphasized that production, in the phenomenological perspective, is understood as a dynamic movement that happens in the world of lived experience (BICUDO, 2000), emphasizing that being human is where we can speak: from mundane reality (HEIDEGGER, 2005). The world as a field of experience and the possibility of the subject to think and express itself opens to understanding and the meanings and meanings are articulated in the acts of experience. The world, always shared with others (beings and objects), is the horizon of possibilities of being and knowing. Within this horizon DT are intentional objects, open to perception and understanding. They are thematized and exposed according to a way of making themselves known.
\end{abstract}

Keywords: Mathematical Education; Phenomenology; Digital Games; Teacher Training.

\footnotetext{
${ }^{1}$ Doutora em Educação Matemática. Professora da Universidade Estadual Paulista (UNESP), campus Guaratinguetá. Guaratinguetá, São Paulo, Brasil. E-mail: rosamonteiropaulo@gmail.com

${ }^{2}$ Doutoranda do Programa de Pós-Graduação em Educação Matemática da Universidade Estadual Paulista (UNESP). Brasil. Professora do Insituto Federal de Itaquaquecetuba (IFSP), Itaquaquecetuba, São Paulo, Brasil. E-mail: ingfirme@gmail.com

${ }^{3}$ Doutor em Educação Matemática. Professor da Faculdade de Informática e Administração Paulista (FIAP), São Paulo, São Paulo, Brasil. E-mail: cristoneis@gmail.com
} 
DOI: http://dx.doi.org/10.33238/ReBECEM.2019.v.3.n.1.21925

\section{Introdução}

Há muito tempo, o contex to escolar vem exigindo mudanças que envolvam o uso das Tecnologias Digitais. Essas mudanças estão expressas, por exemplo, em políticas públicas e documentos oficiais que enfatizam, para a formação do estudante de Ensino Fundamental, no que tange as tecnologias, a compreensão de suas potencialidades e implicações na sociedade. Para os estudantes de nível Médio, recomenda-se que sejam desenvolvidos conhecimentos "cientifico-tecnológicos dos processos produtivos, relacionando a teoria com a prática, no ensino de cada disciplina". (LDB- Lei $\mathrm{N}^{\mathrm{o}}$ 9.394/96).

A cultura digital é parte da vida de muitos estudantes. Computadores, jogos digitais, celulares e redes sociais estão no cotidiano desses jovens de tal modo que seu uso está relacionado à sua vida social. São jovens que fazem parte de um grupo crescente que Prensky (2001) denominou "nativos digitais", considerando aqueles que vivenciam o universo digitral desde muito cedo e que apresentam potencialidades e características distintas de pessoas de gerações anteriores. Tezani (2017), focando estudos realizados por diferentes pesquisadores que discutem essas características dos nativos digitais, ressalta que elas são basicamente relacionadas às habilidades de uso das tecnologias como a capacidade de receber informações rapidamente e a familiaridade com o manuseio do computador, com games e conexão com a internet.

Considerando as ideias de Prensky (2001), os nativos digitais têm habilidade para o uso de recursos tecnológicos e competência para realizar muitas tarefas ao mesmo tempo (multitaskers), estão habituados a receber grande quantidade de informação, o que pode beneficiar a sua aprendizagem. Em decorrência de suas habilidades com as tecnologias digitais têm "[...] preferências de aprendizado para as quais a educação tradicional é despreparada e inadequada" (KIRSCHNER; DE BRUYCKERE, 2017, p. 136, tradução livre).

Os educadores, ao reconhecerem tais características dos nativos digitais, podem organizar ações de ensino voltadas para essas habilidades. Mas, esses educadores não são nativos digitais! Sim, eles são “imigrantes digitais”, segundo Prensky (2001). Logo, a eles é dado o desafio de entender as características dessa nova geração, a despeito de serem excluídos do processo. Ou seja, os professores, como "estrangeiro em novas terras", devem procurar modos de se comunicar com seus alunos sob o risco de não serem ouvidos 
DOI: http://dx.doi.org/10.33238/ReBECEM.2019.v.3.n.1.21925

e, considerando a relevância de sua profissão, de não terem êxito em sua tarefa de ensinar. Logo, as Tecnologias da Informação e Comunicação (TIC), afirmam documentos oficiais, devem ser acrescidas à formação de professores.

No entanto, é possível lançar o olhar em outra direção. Apesar da ideia de nativo digital ter sido divulgada e repetida inúmeras vezes em trabalhos acadêmicos, um relatório publicado a partir de várias pesquisas (ROWLANS et al., 2008), afirma que ela foi superestimada e assumida sem a devida cautela. Ou seja, nesse relatório se discute que os nativos digitais, embora tenham habilidade para o uso das tecnologias, carecem das competências para avaliar a informação que buscam na internet, por exemplo.

Kirschner e De Bruyckere (2017), publicam uma revisão de literatura a respeito da ideia de nativo digital e concluem que há uma crença acerca das capacidades das pessoas que nasceram na era digital que se aproximou de um mito. Citam a capacidade da multitarefa associada à predisposição do sujeito para criar links e ver a informação em rede ou entrelaçada e destacam que a facilidade de acesso simultâneo não implica em atenção e não significa que os sujeitos avaliem a qualidade dos dados obtidos, podendo acarretar em perda do sentido do que se faz. Assim, no contexto educacional, segundo esses autores, a capacidade multitarefa dos nativos digitais pode não ter grande relevância se considerada em si, isto é, sem estar relacionada com a competência critica, pois se trata de uma competência técnica, para o uso que não necessariamente traz desenvolvimento cognitivo e clareza para a aprendizagem.

Além disso, os autores destacam que conhecer essas características da geração de nativos digitais, tem consequências tanto para o ensino quanto para a formação de professores, já que é preciso considerar que "as habilidades e competências atribuídas a essa geração de estudantes são as mesmas que quaisquer outras habilidades e competências, ou seja, elas precisam ser ensinadas e adquiridas adequadamente como qualquer outra" (KIRSCHNER; DE BRUYCKERE, 2017, p. 137, tradução livre).

Relativamente à formação de professores, Kirschner (2015) destaca que, enquanto as tecnologias digitais ${ }^{4}$ forem consideradas um acréscimo à formação e não parte integrante dela, não se pode discutir ensino ou aprendizagem com tecnologias digitais,

\footnotetext{
${ }^{4}$ As tecnologias da informação e comunicação (TIC) envolvem variados recursos como computador ou software, mas também lousa e giz ou lápis e papel. Por outro lado, as tecnologias digitais (TD) é um termo utilizado para referir-se, mais especificamente, aos recursos digitais (software, jogos digitais, internet, etc.).
} 
DOI: http://dx.doi.org/10.33238/ReBECEM.2019.v.3.n.1.21925

sob o risco de elas serem, como para a geração nativos digitais, apenas um recurso para o qual se tenha habilidade de uso.

Com isso, considera-se que quando se discute a formação de professores para ensinar com tecnologias digitais, deve-se levar em conta a ação docente, em uma perspectiva que se volte para o aluno, para a sua aprendizagem, destacando "se" e "como" as tecnologias são potencializadoras - não recursos à mão - de um ambiente de aprendizagem no qual os argumentos para a mudança da prática não se assente em características de uma geração, - de "nativos digitais" - mas sejam condições de possibilidade para a produção de conhecimento (KIRSCHNER, 2015).

Mas o que significa dizer que as tecnologias não devem ser "recursos à mão"? Qual o sentido que as tecnologias digitais têm para a produção de conhecimento, especificamente o conhecimento em matemática? Essas são questões das quais iremos nos ocupar neste texto, tendo sempre como fundo a questão formativa e subsidiados por uma postura assumida: a fenomenológica.

\section{O sentido das Tecnologias Digitais em uma perspectiva fenomenológica}

As tecnologias digitais têm mudado muitos aspectos e visões acerca de sua inserção no ambiente escolar. Desde projetos como, em 1989, o Programa Nacional de Informática Educativa (PROINFE) ou em 1997 o Programa Nacional de Informática na Educação (PROINFO), as discussões acerca do sentido das tecnologias e da formação de professores foram significativamente ampliadas.

Essas discussões, em 2005, levam o Brasil a assumir o Programa Um Computador por Aluno (PROUCA) cujo objetivo era "inserir, nas escolas da rede pública de ensino, o laptop educacional com acesso à internet, vendo-o como uma ferramenta poderosa para a melhoria da educação e para a inclusão digital" (FIRME, 2015, p. 32).

Esses Programas e mais especificamente o PROUCA, foram ações de política pública, cujo objetivo era o trabalho com as tecnologias digitais nas escolas de educação básica, inclusive contemplando a formação de professores. Em 2007 o PROUCA se inicia, em fase pré-piloto, em 05 escolas do território nacional e em 2010, já na segunda fase do Programa, há a aquisição de 150 mil computadores e a inclusão de cerca de 300 escolas, ditribuidas em todos os estados do país. No entanto, as ações consideravam o que potencializava as tecnologias, mas sem modificação do currículo. 
DOI: http://dx.doi.org/10.33238/ReBECEM.2019.v.3.n.1.21925

\begin{abstract}
Os ciberavestruzes que fazem a política escolar estão determinados a usar computadores, mas só conseguem imaginá-los na estrutura do sistema escolar como eles o conhecem: crianças seguindo um currículo escolar predeterminado, especificado ano a ano e lição a lição. Isto é algo perverso: nova tecnologia sendo usada para fortalecer um método pobre de educação, que foi inventado somente porque não havia computadores quando a escola foi pensada (PAPERT, 1997, p. 25).
\end{abstract}

A máquina, o computador, não pode ser entendida apenas como um material didático, pois isto implicaria em uma mesma pedagogia e mesma linguagem sob uma pretensa "modernização" que previa a "inclusão digital". A presença do computador no ambiente escolar não inclui; o que inclui é a linguagem e a produção de significados. A linguagem carece da compreensão de um modo de "ser com a tecnologia digital" que exige uma pedagogia que favoreça a produção de significado.

Nesse sentido, apesar do investimento feito em infraestrutura das escolas e nos cursos para os professores, o que se vê é a intenção de ter os recursos tecnológicos no ambiente escolar e uma formação de professores que está longe do que se espera ser uma educação tecnológica, conforme afirmam Orlovski, Kalinke e Mocrosky (2014, p. 81). Segundo esses autores, as ações desenvolvidas com vistas à inclusão digital foram limitadas, uma vez que "do ponto de vista da formação de professores /.../ o modo como a proposta vem se realizando não contempla a discussão e o entendimento do que /.../ [a tecnologia] pode possibilitar tanto à formação do aluno quanto a do professor em termos de cultura digital".

Mas, o que isso significa? Orlovski, Kalinke e Mocrosky (2014) esclarecem que os Programas dão um enfoque à formação de professores para ensinar com as tecnologias, evidenciando a colaboração e "a necessidade de ações com os professores e não para os professores" (p. 75, grifo dos autores), o que denuncia a falta de envolvimento dos professores nas ações formativas.

Marques (2009), ao analisar a formação oferecida pelo PROUCA, também conclui que ela prioriza os aspectos instrumentais - de uso - em detrimento de discussões das potencialidades para ensinar e aprender com tecnologias digitais. O mesmo é apontado na pesquisa de Firme (2015), em que os professores participantes da formação do PROUCA declaram que consideram os cursos viáveis “[...] em termos de conhecimento da tecnologia, como recurso, uma vez que aproveitavam os encontros desenvolvendo conceitos básicos de informática" (FIRME, 2015, p. 111). 
DOI: http://dx.doi.org/10.33238/ReBECEM.2019.v.3.n.1.21925

Entendemos que, a partir dessas ações de formação oferecidas pelos Programas, desenvolve-se nos professores uma concepção de tecnologia, ou seja, como o enfoque dos cursos estava na instrumentalização ou no uso de recuros de informática, os professores passaram a ver a tecnologia como uma ferramenta disponível para modificar o que fazem, segundo algumas características específicas, por exemplo, a rapidez ou a forma de expor o conteúdo. Portanto, sendo recurso ou ferramenta ela pode ou não ser utilizada.

Porém, se, como Bonilla (2002), considerarmos que a inserção das tecnologias digitais na escola precisa se voltar tanto para a estrutura da escola quanto para as ações do professor, elas (as tecnologias) não serão apenas ferramentas disponíveis para se fazer o mesmo de forma diversa e as ações formativas devem ir em outra direção, oportunizando,

[...] além do acesso às tecnologias, condições de compreender suas características e potencialidades, tendo claro que compreender significa mais do que fazer funcionar, significa inseri-las no contexto do mundo contemporâneo, penetrar nessa nova linguagem, nessa nova lógica, nesse novo modo de ser, pensar e agir (BONILLA, 2002, p. 8).

Interpretamos que, pelas tecnologias digitais, o sujeito amplia suas possibilidades de ser no mundo de tal forma que se torna,

[...] impossível separar o humano de seu ambiente material [no sentido físico], assim como dos signos e das imagens [no sentido cognitivo] por meio dos quais ele atribui sentido à vida e ao mundo. Da mesma forma, não podemos separar o mundo material - e menos ainda sua parte artificial - das ideias por meio das quais os objetos técnicos são concebidos e utilizados, nem dos humanos que os inventam, produzem e utilizam (LÉVY, 1999, p. 22).

Isso indica que, juntamente com a concepção de tecnologia, atrela-se uma visão de formação que, para nós, em uma perspectiva fenomenológica, mostra-se como um movimento no qual a forma de ser professor é dinâmica e se constitui na experiência vivida. É, como diz Bicudo (2003), uma forma/ação, termo cunhado pela autora para dizer da forma (ou do formato) do que aparece mediante um ato atualizador no qual está presente,

[...] um jogo entre ideal, entendido como forma que imprime direção, ação, movida pela força imperante que vigorosamente impele a pessoa para um ato, e que brota do sentimento de dever e de orgulho, por ter conseguido tornar-se o que se tornou, e matéria, constituída pela realidade de vida do povo, que abrange sua historicidade, seus mitos, seus modos de advertir, de impor preceitos, comunicar conhecimentos e aptidões profissionais (BICUDO, 2003, p. 31). 
DOI: http://dx.doi.org/10.33238/ReBECEM.2019.v.3.n.1.21925

A formação de professores, para ensinar com tecnologias digitais, deve toma-la como um meio através do qual se tem a possibilidade de efetuar ações, de coexistir, de estar em sintonia, para que as ações do sujeito sejam condição de possibilidades. Não se trata de usar as tecnologias, mas de ser-com tecnologias. Bicudo e Rosa (2013), retomando Heidegger (1999), dizem que o ser-com é

[...] uma concepção que expõe o fato de sempre já sermos com o que nos circunda, pois somos em uma espacialidade em movimento de ser, portanto, sendo, junto ao que conosco também está sendo. "Isso" com o que sempre estamos sendo de modo constitucional abrange seres humanos e não humanos, objetos culturais, instrumentos e por aí vai. Esse autor [Heidegger] traz a concepção de não sermos separados do que conosco está na espacialidade mundana de nossa existência (BICUDO; ROSA, 2013, p. 70).

Logo, ser-com diz de um modo de o humano ser no mundo o que implica em seraí com algo (pessoas ou objeto) e, “[...] na base desse ser-no-mundo determinado pelo com, o mundo é sempre o mundo compartilhado com os outros. O mundo da pre-sença ${ }^{5}$ é mundo compartilhado. O ser-em é ser-com os outros" (HEIDEGGER, 2005, p. 170). E, considerando que o humano jamais é um ser acabado, uma vez que sempre está aberto a uma gama de possibilidades sobre as quais se projeta, suas ações “[...] tratam-se de uma projeção no mundo, do mundo e com o mundo, de tal forma que o eu e o mundo são totalmente inseparáveis" (HEIDEGGER, 1999, p. 7, grifos do autor).

Heidegger, um filósofo cuja obra nos permite pensar o sentido do ser, do humano, faz uma crítica ao domínio da técnica, destacando que não se pode perder o espaço essencial do humano. Com seu pensar pretende "[...] impedir que a razão se instrumentalize inteiramente e se perca a visão do todo" (HEIDEGGER, 1999, p. 18). As tecnologias digitais, se considerarmos a possibilidade de o humano ser-com, não é um mero artefato com o qual estabeleço certa relação; o artefato - e nosso relacionamento com ele - já é o resultado de uma maneira tecnológica particular de ver e de me conduzir em direção ao mundo. As tecnologias digitais não são coadjuvantes no processo de ensinar ou aprender, elas modificam o ambiente escolar e os sujeitos nele envolvido; modificam os modos pelos quais os sujeitos se comunicam, caracterizando uma nova forma de pensar e de conceber o conhecimento (LÉVY, 1999).

Logo, uma formação de professores para ensinar com tecnologias não deve se pautar no seu preparo para usar o computador ou para apenas conhecer o software, não

\footnotetext{
${ }^{5} \mathrm{O}$ termo pre-sença em Heidegger (2005, p. 33) designa "esse ente que cada um de nós somos e que, entre outras, possui em seu ser a possibilidade de questionar".
} 
DOI: http://dx.doi.org/10.33238/ReBECEM.2019.v.3.n.1.21925

deve fixar-se na execução de atividades elaboradas para o ensino com tecnologias, devese, contrariamente a isso, considerar o modo pelo qual, na era da tecnologia, se pode produzir conhecimento.

E, considerando pela perspectiva fenomenológica, vale ressaltar, com Bicudo (2014), que no modo de o humano ser-com, as tecnologias não sendo recursos ou ferramentas são objeto intencional, que abrem à compreensão da produção de conhecimento do sujeito ao estar-com as TD.

\section{As tecnologias digitais e a produção de conhecimento}

Lévy, já em 1999, afirmava que o espaço inaugurado pelas tecnologias - o ciberespaço - dinamiza o modo pelo qual o sujeito tem acesso a informação, de forma que o planejamento do como e do o que deve ser ensinado não terá condições de acompanhar a velocidade das informações que são, diariamente, atualizadas. Logo, mais do que se preocupar com o planejamento de estratégias e conteúdos o professor deve priorizar o sentido que a tecnologia pode ter para a formação do sujeito, para a vida em sociedade.

Ainda, para Lévy (1999), a relação entre tecnologia e saber exige uma análise prévia que considere três aspectos:

\footnotetext{
[...] a velocidade de surgimento dos saberes e saber-fazer /.../ a nova natureza do trabalho, /.../ [onde] trabalhar quer dizer, cada vez mais, aprender, transmitir saberes e produzir conhecimentos /.../ [e o fato de que] o ciberespaço suporta tecnologias intelectuais que amplificam, exteriorizam e modificam numerosas funções cognitivas humanas: memória (bancos de dados, hiperdocumentos, arquivos digitais de todos os tipos), imaginação (simulações), percepção (sensores digitais, telepresença, realidades virtuais), raciocínios (inteligência artificial, modelização de fenômenos complexos) (LÉVY, 1999, p. 157).
}

Destaca que duas grandes reformas são necessárias ao ensino: uma que considere a inserção das tecnologias (com os instrumentos ou equipamentos necessários) e outra que pondere o ensino a distância. Para o autor, com as tecnologias, a escola perde o monopólio da "criação e transmissão de conhecimentos" devendo, portanto, assumir para si o papel de orientar as aprendizagens individuais.

Esses dizeres nos chamam a atenção, tanto pelo que acima acabamos de discutir, acerca do modo pelo qual as tecnologias são, de modo geral, vistas como recurso ou ferramentas, quanto pela forma como o conhecimento e, mais precisamente, a produção de conhecimento, pode ser compreendida. Se voltarmos às considerações de Tezani, (2017) vemos que a competência para o acesso a informação, desenvolvida na geração da 
DOI: http://dx.doi.org/10.33238/ReBECEM.2019.v.3.n.1.21925

era tecnológica, não é garantia de conhecimento. Conhecimento e informação são de natureza distinta. O que a era tecnológica possibilita, sem sombra de dúvidas, é o acesso à informação.

O conhecimento, conforme salienta Ferreira (2019, p. 43), é o que “[...] se constitui no mundo humano da experiência vivida" ou, ainda, citando Heidegger (2005, p. 100), o conhecimento é o que “[...] se funda previamente num 'já-ser-junto-aomundo $\%$... [possibilitando] que a pre-sença se constitua de modo essencial". Porém, o jáser-junto-ao-mundo não é um modo passivo de se estar no mundo em estado contemplativo ou de observação de algo que acontece em certo lugar chamado mundo. Conhecer é uma atividade da pre-sença que percebe, conserva e mantém, uma vez que "[...] o que se percebe e determina pode ser pronunciado em sentenças e manter-se e preservar-se nessa qualidade de proposto" (HEIDEGGER, 2005, p. 101).

Esse modo de compreender o conhecimento em uma postura fenomenológica, "[...] configura-se como uma produção, construído, não imposto" (ANASTÁCIO, 1999, p. 134, grifo nosso). A produção, de acordo com Heidegger (1996, 2005), pode ser entendida segundo duas perspectivas: aquela que traz o sentido grego ou o da racionalidade moderna. Orlovski, Kalinke e Mocrosky (2014, p. 85), distinguem esses sentidos.

O sentido grego de produção, segundo esses autores, diz de um ver claro, ou seja, o sujeito que se volta atentamente para um objeto o vê com clareza, tal qual ele se mostra. Há, nesse modo de ver claro, uma abertura ${ }^{6}$ de possibilidades, de elaboração e projeção do que é visto. Já na pespectiva da racionalidade moderna a produção é entendida com um caráter mais instrumental que envolve a técnica, o valor utilitário que expõe o produzido para o uso. Esses modos de compreender a produção trazem, de um lado, o "vir a ser" como abertura, e de outro lado, o "fazer ser" como um ideal ou um caminho antevisto para o modo de ser (ORLOVSKI; KALINKE; MOCROSKY, 2014).

Destacamos, porém, que na postura fenomenológica, entende-se que o conhecimento é possibilitado pela percepção, pela vivência do sujeito que é no mundo com os outros (seres ou objetos), pelos atos reflexivos que são favorecidos pela disposição

\footnotetext{
${ }^{6}$ Os termos abertura e abrir em Heidegger (1999, p. 118) são considerados para dizer de um modo de “'des-trancar' [em que] 'abrir' jamais significa, portanto, algo como 'concluir através de mediações"”.
} 
do sujeito, então a produção de conhecimento é algo dinâmico que não se deixa restringir por um fazer técnico, já que,

[...] ao conhecer, a pre-sença adquire uma nova posição ontológica, no tocante ao mundo já sempre descoberto. Esta nova possibilidade ontológica pode-se desenvolver autonomamente, pode-se tornar uma tarefa e, como ciência, assumir a direção do ser-no-mundo. Todavia, não é o conhecimento quem cria pela primeira vez um "commercium" do sujeito com um mundo e nem este commercium surge de uma ação exercida pelo mundo sobre o sujeito. Conhecer, ao contrário, é um modo da pre-sença fundado no ser-no-mundo (HEIDEGGER, 1999, p. 102, grifos do autor).

Desse modo, produzir conhecimento com tecnologias exige que a consideremos (as tecnologias) como um modo de desabrigar que possibilita o vir a ser. Logo, não é mais um modo técnico de considerar habilidades para o manuseio de equipamentos ou de software, é algo que envolve tudo isso e vai além; traz o sentido da techné que diz de "[...] um fazer pelo saber, um modo de produzir que está intimamente ligado ao conhecimento" (FERREIRA, 2019, p. 53), uma forma de levar do ocultamento ao desocultamento, de pensar, de agir, de expor modos de compreender que exige atitude, postura, desafios enfrentados nos modos de o humano ser-com.

Esses modos de o humano ser-com é o que temos perseguido nas pesquisas desenvolvidas, quer seja com a formação de professores, quer seja com o trabalho na sala de aula da Educação Básica. Neste texto trazemos um recorte do feito, procurando exemplificar o modo pelo qual se está desenvolvendo esse modo de ser-com para a produção de conhecimento.

\section{Os jogos digitais: perspectivas abertas à compreensão das tecnologias}

Brown (2009), psiquiatra e pesquisador em brincadeiras e jogos, apontou a ação de brincar como um fator essencial ao desenvolvimento criativo, destacando, em suas pesquisas, que a ausência de tempo e espaço para as atividades lúdicas, principalmente na infância, pode comprometer a capacidade humana de aprender, a empatia e o que chamamos de felicidade, pois o jogar e o brincar estão intrinsicamente relacionados com a satisfação pessoal. Corroborando essa ideia, Wenner (2009) afirma que o brincar e o jogar incentivam a criatividade e a curiosidade.

Nisso, algumas pesquisas tem discutido as potencialidades dos jogos para o ensino e a aprendizagem matemática (GRANDO, 2007, 2009, 2015), destacando-os como espaço de investigação. Dos jogos convencionais, como os de tabuleiro, por exemplo, ao 
DOI: http://dx.doi.org/10.33238/ReBECEM.2019.v.3.n.1.21925

jogo digital ou game, Salen e Zimmerman (2003) elencam quatro características que possibilitam vivências distintas ao jogar um jogo: a interatividade imediata (ainda que limitada), a manipulação de informação, a automatização de sistemas complexos e a comunicação em rede.

Os games são, portanto, interativos, oferecem experiências imediatas e podem ter narrativas não lineares se sua estrutura for hipertextual, caracterizando-se como espaço em que, pela ação de jogar, hipóteses sejam levantadas, argumentos construídos e ideias expressas. Como afirmou Schoenfeld (1996, p. 11) “[...] das Artes à Literatura, à Física o que deveria ser aprendido são múltiplos caminhos de ver o mundo, e os variados instrumentos interdisciplinares e perspectivas que nos ajudam a entendê-lo". O jogo, entendido como uma atividade livre e, portanto, motivada pelo desejo de explorar, conhecer e divertir, é uma perspectiva possível para se perceber o mundo virtual, isto é, potencial.

A percepção, tal como ela é entendida na perspectiva fenomenológica é, segundo Merleau-Ponty (2006), o que funda ou inaugura o conhecimento, uma vez que,

[...] tudo aquilo que sei do mundo, mesmo por ciência, eu o sei a partir de uma visão minha ou de uma experiência do mundo sem a qual os símbolos da ciência não poderiam dizer nada /.../ A percepção não é uma ciência do mundo, não é nem mesmo um ato, uma tomada de posição deliberada; ela é o fundo sobre o qual todos os atos se destacam (MERLEAU-PONTY, 2006, p. 3-7).

No jogar o jogo, o pensar, o agir, o fazer, o planejar, são atos de um mesmo movimento que visam resolver um problema ou transpor um desafio a partir de uma situação que se abre na percepção. O jogo dispõe o sujeito para... o faz atento a. Nesse dispor-se ele joga, investiga, dialoga e se lança. Instaura-se o movimento do pensar criador que atribui significado às ações.

A pesquisa de Tonéis (2016) mostra que a presença de puzzles nos jogos digitais, se caracteriza com estrutura fundamental para a constituição de conhecimento ${ }^{7}$ pelo sujeito, pois “[...] o desenvolvimento das habilidades de observação, abstração, generalização e simulação estão intrinsecamente ligados à resolução de problemas” (TONÉIS, 2016, p. 406).

\footnotetext{
${ }^{7}$ Conforme Rosa e Bicudo (2018, p. 42) a constituição se difere da produção uma vez que “[...] diz da articulação dos dados sensórios, sentidos que fazem ao corpo-encarnado e que vão se articulando na própria carnalidade desse corpo, e no movimento dessa articulação vai definindo unidades, percebendo fenômenos e articulando e expressando compreensões".
} 
DOI: http://dx.doi.org/10.33238/ReBECEM.2019.v.3.n.1.21925

A resolução de puzzles que estão imersos em uma narrativa oferece ao jogador um espaço para ação. Por meio de pistas (identificação de dados, percepção), hipóteses ou conjecturas são levantadas. No diálogo com o outro (jogo, colega ou professor) se busca estabelecer um processo de verificação (feedback) que permita atestar a validade do caminho escolhido ou reorganizar a ação.

Quando em um game encontramos um espaço propício para a investigação, então esse game pode apresentar-se como um caminho para a produção de conhecimento, pois tem potencialidade para a sistematização, que expõe o compreendido e dialogado. A seguir destacamos alguns games, visando explorar essa possibilidade de encontro sercom as tecnologias digitais.

O Alkimya (indicado como o melhor jogo Brasileiro 2018 ${ }^{8}$ ) é um jogo indie brasileiro de ação e aventura, desenvolvido pelo estúdio brasiliense Bad Minions.

Figura 1: Alkimya

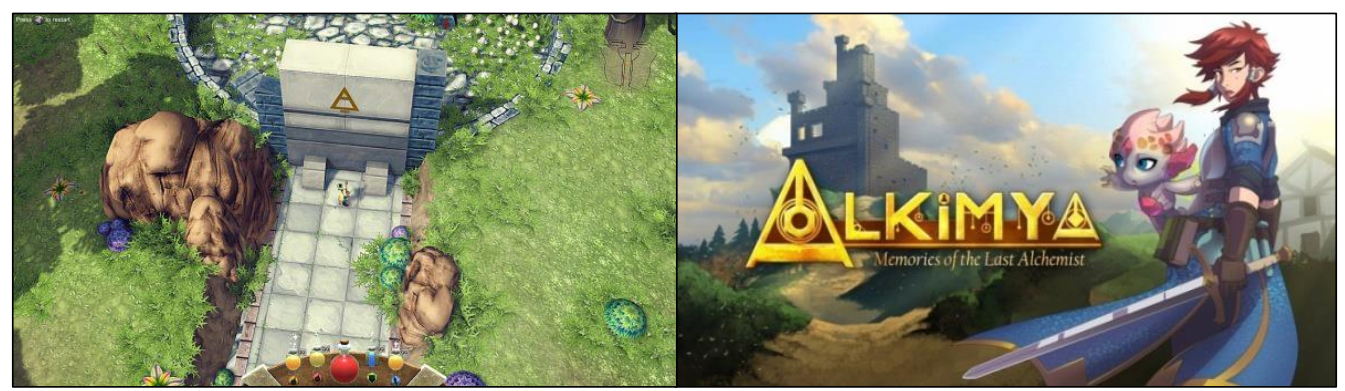

Fonte: Disponível em: <https://store.steampowered.com/app/521620/Alkimya/>. Acesso em: 08 mar. 2019.

No papel do protagonista Seth, que acorda sem memória em um lugar desconhecido, o jogador poderá explorar e desvendar os mistérios do ambiente. O game é totalmente interativo e pode ser comparado a outros como Magicka, The Legend of Zelda, Full Metal Alchemist e CD Projekt Red. Sua jogabilidade pode parecer simples, porém faz parte do envolvimento interativo, já que em um game é importante termos novidades e similaridades em sua mecânica e jogabilidade. Podemos quebrar objetos do cenário para conseguir a matéria prima para fazer as poções que serão utilizadas na batalha contra os monstros e para resolver puzzles. Essas poções podem ser bombas ou tônicos, dependendo do objetivo. Ninguém está sozinho na jornada, pois uma criatura voadora e brilhante chamada Pan, estará ajudando nos combates, na resolução dos puzzles

\footnotetext{
${ }^{8}$ BIG 2018. O game também foi aprovado no Steam Greenlight. Mais informações podem ser obtidas no site <https://www.kickstarter.com/projects/1840539377/alkimya-alchemy-action-adventure-game>).
} 
DOI: http://dx.doi.org/10.33238/ReBECEM.2019.v.3.n.1.21925

e na coleta de recursos. $\mathrm{O}$ game explora a imaginação e criatividade, valorizando a tomada de decisão.

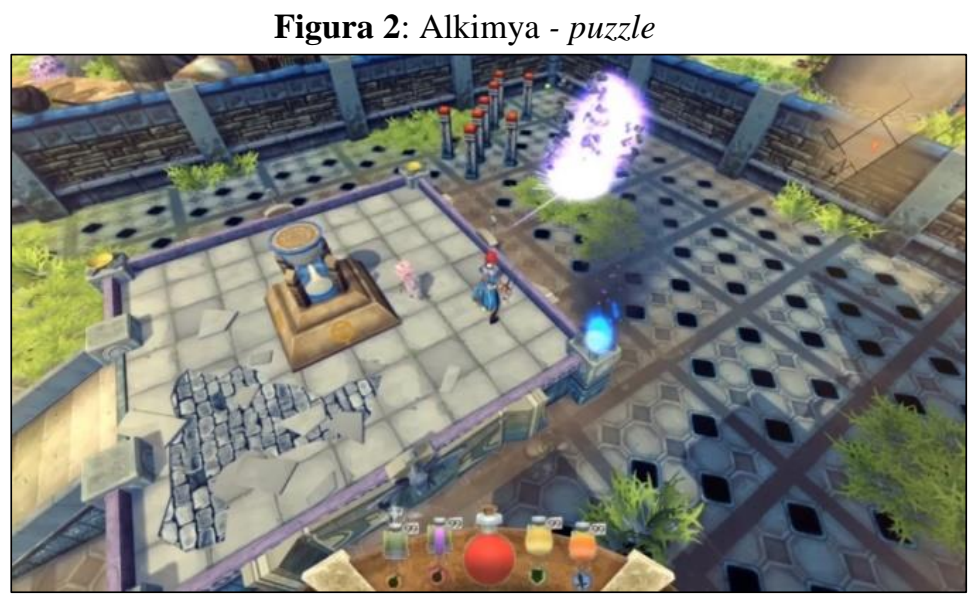

Fonte: Disponível em: <https://store.steampowered.com/app/521620/Alkimya>. Acesso em: 08 mar. 2019

A Ubiart trouxe com Child of Light um ambiente que mistura Role-Playing game (RPG) e ação. Enfrentando monstros e criaturas mágicas no reino de Lemuria, o protagonista - Princesa Aurora - luta para derrotar o mal. Além dos poderes que são adquiridos ao longo do game, as batalhas envolvem estratégia (puzzles) e poder, oferecendo uma jogabilidade desafiadora em meio a um cenário e trilha sonora cativantes.

Figura 3: cenários de Child of Light

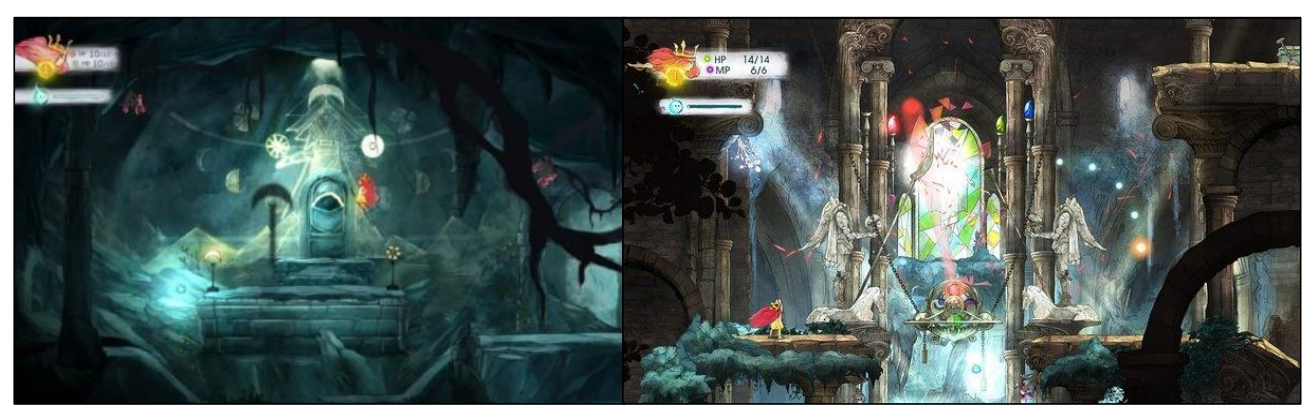

Fonte: Disponível em: <https://www.ubisoft.com/pt-br/game/child-of-light/>. Acesso em: 10 de mar. 2019

Podemos afirmar que algumas batalhas são verdadeiros puzzles, pois não se trata apenas de vencer (uma batalha), mas de analisar, compreender e agir diante de um obstáculo. Em alguns momentos o ritmo pode variar, como em jogos de RPG.

O jogar um jogo, especificamente um jogo digital, pela sua característica dinâmica e interativa, seja em projetos multidisciplinares ou no contexto da sala de aula, mais do que abrir-se a exploração de um conteúdo, dá possibilidade para discutir atitudes e modos de sujeito se envolver com a ação. Pelo jogo é possível potencializar o desenvolvimento 
DOI: http://dx.doi.org/10.33238/ReBECEM.2019.v.3.n.1.21925

de habilidades como a percepção, a análise de situações, a tomada de decisão tendo como meta a expressão do vivenciado que abre ao diálogo o compreendido. Os jogos digitais são oportunidades para inserir a TD no universo da sala de aula, trazendo um modo de colocar o sujeito em movimento. Outra possibilidade, embora de natureza distinta, é o trabalho com software.

\section{Situando modos de ser-com as tecnologias: na formação de professores}

Se concordarmos com Orlovski, Kalinke e Mocrosky (2014, p. 85), que a formação de professores para ensinar com tecnologias não dispensa a técnica, mas deve ir além dela, precisaremos “[...] pensar a forma de ser professor, amalgamada à ação do formar", oportunizando a discussão dos modos de ensinar e aprender com tecnologias, para que essa formação não sejá mais para ele e sim com ele.

Com esse pensar nos envolvemos, desde 2016, com processos formativos nos quais aos professores é dada a oportunidade de fazer matemática com tecnologias e pensar os modos de ensinar, aprender e de ser-com tecnologias. As ações são desenvolvidas por meio da parceria Universidade - Escola. Mediante convênio com a Secretaria de Educação do Estado de São Paulo, são propostas ações de formação no modelo de cursos de extensão, para que, aos professores, tenha validade em termos de progressão na carreira. Nesse espaço aberto pelos cursos, os professores conheceram o software GeoGebra e discutiram opções para o ensino de matemática na sala de aula da Educação Básica. Para este texto, faremos um recorte de uma das ações desenvolvidas no ano de 2016, que culminou com a publicação de um $e b o o k^{9}$ ao final de $2018^{10}$.

Detalhamos, aqui, a proposta de um grupo de professores para explorar um caso de semelhança de triângulos, sugerido no Caderno do Professor para alunos do $9^{\circ}$ ano do ensino fundamental - o estado de São Paulo fornece ao professor um material de apoio curricular com atividades para serem desenvolvidas em sala de aula. A escolha do

\footnotetext{
${ }^{9}$ Esse ebook foi publicado no final de 2018. Está organizado em duas partes. Na primeira são trazidos textos que discutem o sentido da formação de professores e da produção de conhecimento com tecnologias. Na segunda parte há artigos produzidos pelos professores participantes do curso que trazem atividades construídas para a sala de aula com arquivos no GeoGebra e videoaulas. O ebook Seer professor com Tecnologias: sentidos e significados, é de acesso gratuito pelo site da Editora da Unesp, selo Cultura Acadêmica (http://www.culturaacademica.com.br/catalogo/ser-professor-com-tecnologias/).

${ }^{10}$ Vale destacar que, embora essa parceria tenha se iniciado em 2016, ainda permanece nos dias atuais e muitos professores continuam conosco pensando e discutindo possibilidades de ensinar e aprender matemática com tecnologias digitais.
} 
DOI: http://dx.doi.org/10.33238/ReBECEM.2019.v.3.n.1.21925

conteúdo se deu após os professores destacarem que, de acordo com o que é sugerido pelo material didático, (SÃO PAULO, 2014-2017, p. 26), “[...] a semelhança de triângulos é o ponto de partida para diversas formalizações na Geometria plana”.

A proposta explora as relações métricas em segmentos inscritos na circunferência (comprimento de cordas ou tangentes), com uma construção feita a partir da intersecção entre cordas que geram segmentos proporcionais, é justificada pelo reconhecimento da igualdade entre a medida de arcos e ângulos correspondentes. A exploração da congruência de arcos e ângulos que determinam os segmentos (secantes ou tangentes) possibilita a análise da semelhança de triângulos (SÃO PAULO, 2014-2017).

O Caderno do Professor apresenta essa tarefa a partir de figuras, desenhos ilustrativos que, em decorrência do material, são estáticas. A intenção do professor é ampliá-la com o GeoGebra para dar dinamicidade, pois consideram que, mediante a manipulação no software, abririam-se novas possibilidades de os alunos levantarem conjecturas que não seriam possíveis pelo desenho, explorando propriedades, discutindo argumentos e buscando modos de validação das hipóteses levantadas. Os professores entenderam ser importante para a aprendizagem dos alunos o envolvimento ativo com a exploração. Há autores que defendem essa perspectiva ativa, dizendo que é importante

[...] estimular o aluno a ter uma participação ativa no processo de ensino, construindo suas próprias percepções em relação aos conteúdos da Geometria. Essa participação é realizada na construção de desenhos, medições, visualizações, comparações, transformações e classificação de figuras, permitindo uma interação ampla com os conteúdos focalizados (NOVAK; PASSOS, 2007, p. 13).

A proposta no GeoGebra começa pela construção da circunferência, usando a ferramenta "Círculo dados centro e raio". O centro é criado a partir de um ponto qualquer da tela e o raio tem medida variando por meio de um controle deslizante " $r$ ". Na sequência são construídos três pontos quaisquer na circunferência e dois segmentos (cordas) com extremidades nos pontos criados. 
DOI: http://dx.doi.org/10.33238/ReBECEM.2019.v.3.n.1.21925

Figura 4: construção de segmentos na circunferência

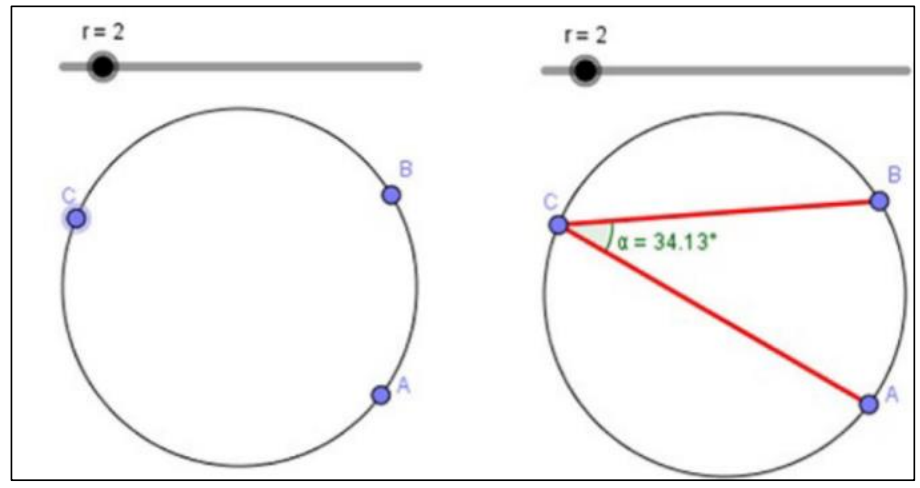

Fonte: do Autor

A partir dessa construção os professores sugerem que sejam feitas explorações, como movimentar os pontos $\mathrm{A}$ e depois $\mathrm{B}$, discutindo a medida do ângulo ACB. Recomendam que, em seguida, seja movimentado o ponto $C$ para verificar se há ou não alteração da medida desse ângulo e argumentar sobre a conclusão. Após essa primeira exploração, deve-se marcar na circunferência o ponto $\mathrm{D}$, construindo os segmentos $\mathrm{AD}$ e BD (cordas). Com a ferramenta ângulo é medido o ângulo ADB.

Figura 5: construção do Angulo ADB

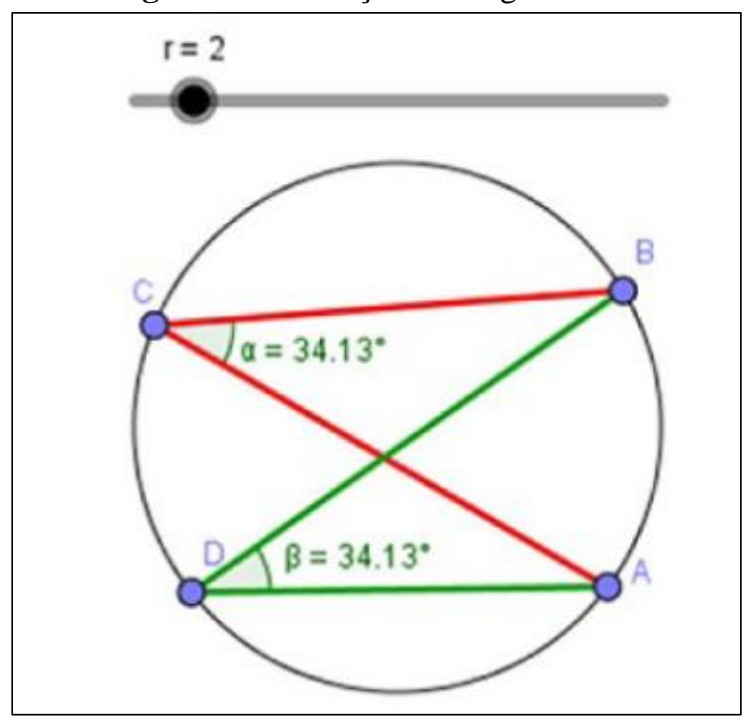

Fonte: do Autor

A movimentação dos pontos na circunferência possibilita concluir que, tanto o ângulo $\mathrm{ACB}$ quanto o ângulo $\mathrm{ADB}$ têm o mesmo arco de circunferência $\mathrm{AB}$, logo possuem a mesma medida. Eles são nomeados: ângulos inscritos na circunferência. 
DOI: http://dx.doi.org/10.33238/ReBECEM.2019.v.3.n.1.21925

Em seguida, sugere-se criar um ponto de interseção das cordas CA e DB, nomeando-o P. Com a ferramenta ângulo são medidos os ângulos BPC e DPA. Novamente movimentando os pontos é possível explorar a igualdade entre a medida desses ângulos denominados ângulos opostos pelo vértice.

Figura 6: ângulos opostos pelo vértice

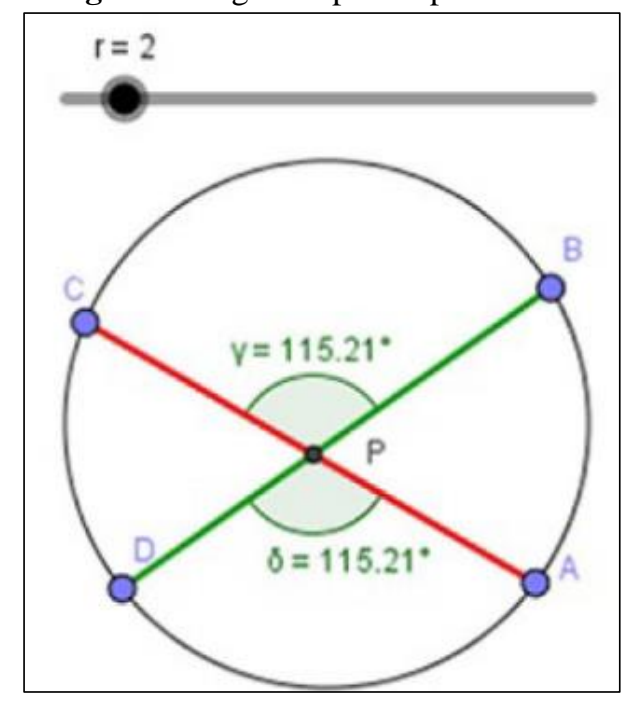

Fonte: do Autor

Aproveitando a construção, os professores decidiram explorar, também, a soma dos ângulos internos de um triangulo. Medindo os segmentos PA, AD, DP, BP, PC e CB e movimentando os pontos A, B, C e D e o raio "r", foi possível explorar a razão entre a medida dos segmentos, organizar os dados e discutir a diferença entre semelhança e congruência de triângulos.

Figura 7: semelhantes ou congruentes?

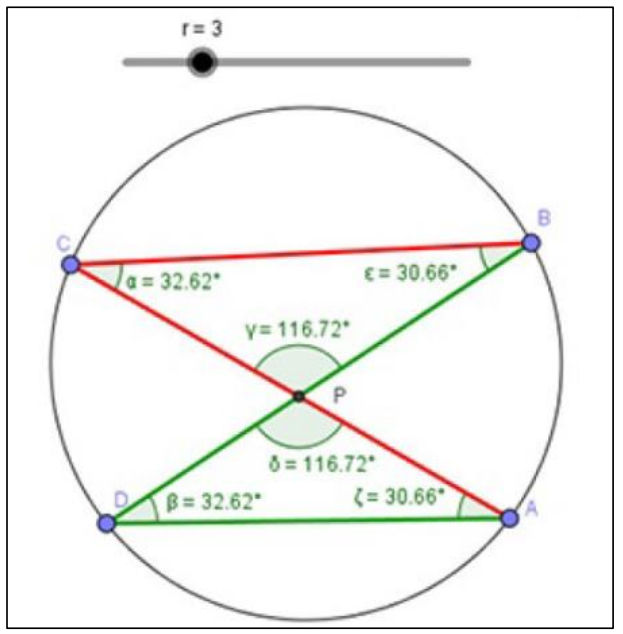

Fonte: do Autor 
DOI: http://dx.doi.org/10.33238/ReBECEM.2019.v.3.n.1.21925

Ao final do curso os professores consideraram que as atividades no GeoGebra contribuem para o desenvolvimento das habilidades de visualização, favorecem a investigação e a compreensão de ideias importantes à aprendizagem geométrica. Concluiram que a validação, requerida para a investigação feita no software, permite a generalização, cabendo ao professor encaminhar a discussão para que o aluno se expresse usando a linguagem matemática.

Discutiu-se com os professores que um dos objetivos do ensino com software de Geometria Dinâmica (GD), como o GeoGebra, é, pelo movimento, analisar os invariantes percebidos ou o que permanece na ação de mover, possibilitando a compreensão do aluno. As ferramentas do software que permitem o "arrastar" abrem opções de o aluno perceber e explorar as implicações de seus atos. Como afirma Pinheiro (2018, p. 70), “[...] o ato de arrastar realizado [pelo] sujeito em ambientes de [Geometria Dinâmica] GD é sempre um arrastar para ..., mesmo que esse movimento, aos olhos de alguém que olha a atividade realizada por esse sujeito, pareça sem sentido, sem objetividade ou meta".

Para nós, mostra-se a relevância do ser-com tecnologias digitais que inicialmente discutiu-se neste texto. O movimento é percebido pelo sujeito que move. Nos jogos esse movimento é distinto: com toque na tela do celular ou tablet (dispositivos touchscreen), o sujeito se move com o movimento do personagem, por exemplo. No software de GD, outros aspectos da percepção, do modo de o sujeito realizar investigações, de dialogar, de expressar o compreendido, se revelam. Podemos considerar que o sentido do movimento nesse trabalho é o de abertura descrito por Heidegger, em que o sujeito se move, movendo-se.

Novamente, chamando a discussão empreendida por Pinheiro (2018), pode-se dizer que essa possibilidade de mover dá-se no ser-com,

[...] quando movemos o mouse, há o mouse visto, há dados visuais do mouse e
de experiências motoras com o mouse que nos permitem movê-lo
compreendendo e controlando o movimento sem olhar para ele. /.../ [Vê-se] o
movimento materializando-se na tela computacional no mesmo tempo e espaço
em que estamos em uma experiência tátil-visual com o mouse. Desta forma,
mesmo estando com meus olhos voltados apenas à tela, mesmo que o mouse
não esteja em meu campo de visão, no agora do ato de mover e ver o
movimento realizado, estou tátil-visualmente com o mouse e com a tela
computacional (PINHEIRO, 2018, p. 71).

Voltamos a destacar que, no toque exigido no jogo ou no movimento do mouse, o que se destaca não é a ferramenta ou o recurso, mas o sujeito que junto os move. Tal qual Merleau-Ponty (2006) diz da bengala do cego, que é uma extensão de seu corpo, já que 
DOI: http://dx.doi.org/10.33238/ReBECEM.2019.v.3.n.1.21925

ele pode sentir o chão, vê-lo ou tocá-lo com sua bengala, entende-se que o sujeito, ao tomar as TD como objeto intencional, tem, por exemplo, o mouse como extensão de seu corpo. No mover há uma "[...] intencionalidade motora que faz constituir-se o movimento e é a precisão motora do corpo, da mão, dos dedos, que controla o movimento" (PINHEIRO, 2018, p. 72).

Desse modo, para nós, mostra-se o sentido de ser-com-tecnologias em que, no jogo ou no GeoGebra, o movimento não é atributo do recurso usado, é condição de possibilidade do sujeito que pode se lançar para, realizar investigações, buscar modos de compreender e interpretar, articulando o visto e expressando, por meio de uma linguagem que visa a validação do que é vivenciado, a objetividade.

\section{Considerações finais}

A constituição de conhecimento, tal como é compreendida na perspectiva fenomenológica, é um movimento complexo que envolve os modos pelos quais o sentido dos atos se faz para o sujeito (ROSA; BICUDO, 2018) e tem como solo a percepção. No movimento perceber-percebido, o objeto intencional, o visado intencionalmente no ato da percepção, se mostra ao sujeito que articula compreensões. O compreendido é expresso pela linguagem que também se abre para compreensões e interpretações de outros sujeitos, pertencentes a uma mesma comunidade. Os atos de conhecer envolvem, portanto, o outro, co-sujeito com quem se dialoga e que "[...] também compreende e pode compreender o dito em uma linguagem articulada e expressa em sua materialidade" (ROSA; BICUDO, 2018, p. 18).

O que é acordado nesse movimento dialógico de co-sujeitos é repetido e se torna objetivado podendo ser retomado e novamente compreendido. Assim,

\footnotetext{
A objetividade do que assim se tornou objetivo não é uma objetividade dada, mas constituída por sujeitos em sua carnalidade, que convivem, se colocam em movimento de saber ou de fazer algo e que têm suas ações materializadas em produtos histórico-sócio-culturais, passível de ser retomado, repetido, compreendido, vivificado em atos sensoriais, psíquicos e espirituais (ROSA; BICUDO, 2018, p. 19).
}

Neste texto buscamos destacar o sentido da produção de conhecimento que enlaça a subjetividade do sujeito pela percepção e a compreensão; a intersubjetividade, no diálogo com o outro expressando o percebido e articulado e a objetividade que, no contexto escolar, visa à validação do interpretado pela construção de argumentos. Ou seja, 
DOI: http://dx.doi.org/10.33238/ReBECEM.2019.v.3.n.1.21925

tal qual entendemos, no contexto escolar, seja ele da aprendizagem do aluno ou da formação de professores, a produção de conhecimento se dá nessa abertura de possibilidades na qual o sujeito percebe e organiza o percebido para expor o que vivencia no mundo da experiência vivida.

Ao considerarmos os games, nas palavras de Santaella (2004, p. 6), entende-se que ele pode ser interpretado como "[...] um mundo possível porque, nele, jogador e jogo são inseparáveis". O jogador apreende as regras implícitas e explícitas no jogo à medida que interage com ele. Esse "interagir" envolve um voltar-se para ..., um estar disposto a ... Da apreensão das regras do game à compreensão das propriedades que nele são características, há um caminho no qual se destaca a importância da produção de significados ou do sentido que o feito tem para o sujeito que se dispõe ao jogar, que se coloca no movimento de estar no jogo e com o jogo. No software perceber-se movendo e identificar variantes e invariantes, possibilita expor “"...] sentidos e significados que, na duração do movimento e do pensar sobre o movimento, vão se ampliando e se entrelaçando" (PINHEIRO, 2018, p. 75).

Se, com Merleau-Ponty (2006), consideramos que somos seres situados e por isso temos a possibilidade de expandir nosso espaço de vivencia, entende-se que as situações do universo digital potencializam nosso modo de ser-com as tecnologias digitais permitindo compreender que, embora não se possa ser "des-escolar", pode-se valorizar as ações do sujeito atentos ao fluxo da temporalidade vivida, aos atos da consciência que se voltam para ... perceber, compreender, interpretar e comunicar, permitindo resignificar nosso próprio modo de agir.

Negroponte (1995, p. 190) afirma que “[...] o aprender fazendo tornou-se regra, e não exceção". Com isso, assumiu que o protagonismo é essencial em qualquer atividade tornando-se imprescindível para as novas gerações, cujo acesso a informação está "na palma da mão". Mas, esse protagonismo, se for entendido como ação do sujeito, da “[...] consciência [que] se estende ao fenômeno e o traz como percebido para si, articulando mediante seus atos das esferas sensorial, psíquica e espiritual, compreensões sobre o mesmo" (ROSA; BICUDO, 2018, p. 17), potencializa modos de ser-com tecnologias digitais.

O que procuramos trazer neste texto foca esse modo de ser-com na formação de professores com implicações para a sala de aula, valoriza as ações do aluno ou do 
DOI: http://dx.doi.org/10.33238/ReBECEM.2019.v.3.n.1.21925

professor, protagonistas, sujeitos da percepção. Mas, tanto quanto valorizar o "como se faz" deve-se enfatizar o "perceber-se fazendo" que oportuniza a expressão e lança luz aos modos de o sujeito conhecer.

\section{Referências}

ANASTÁCIO, M. Q. A. Três Ensaios numa articulação sobre a racionalidade, o corpo e a Educação Matemática. 1999. Tese (Doutorado em Educação) - Faculdade de Educação, Universidade Estadual de Campinas, Campinas, 1999.

BICUDO, M. A. V. Fenomenologia confrontos e avanços. São Paulo: Cortez, 2000.

BICUDO, M. A. V. Formação do professor: um olhar fenomenológico. In: BICUDO, M. A. V. (org.). Formação de Professores? Da incerteza à compreensão. Bauru: EDUSC, 2003. p. 7-46.

BICUDO, M. A. V. Meta-análise: seu significado para a pesquisa qualitativa. Revemat: Revista Eletrônica de Educação Matemática, Florianópolis, v. 9, p. 7-20, 2014.

BICUDO, M. A. V; ROSA, M. A presença da Tecnologia na Educação Matemática: efetuando uma tessitura com situações-cena do filme Avatar e vivências em um curso a distância de formação de professores. Alexandria, Florianópolis, v. 6, p. 61-104, 2013.

BONILLA, M. H. Inclusão Digital e formação de professores. Revista de Educação, Lisboa, v. XI, n. 1, p. 43-50, 2002.

BRASIL. Lei de Diretrizes e Bases. Lei no 9.394/96, de 20 de dezembro de 1996.

BROWN, S. L. Play: How it shapes the brain, opens the imagination, and invigorates the soul. Penguin, 2009.

FERREIRA, M. J. A. A produção do conhecimento matemático ao ser-com as Tecnologias Digitais. 2019. Tese (Doutorado em Educação Matemática) - Instituto de Geociências e Ciências Exatas, Universidade Estadual Paulista, Rio Claro, 2019.

FIRME, I. C. A atualização do PROUCA nas escolas estaduais do Estado de São Paulo. 2015. Dissertação (Mestrado em Educação Matemática) - Instituto de Geociências e Ciências Exatas, Universidade Estadual Paulista, Rio Claro, 2015.

GRANDO, R. C. Concepções quanto ao uso de jogos no ensino da Matemática. Revista de Educação Matemática, São Paulo, v. 10, p. 45-52, 2007.

GRANDO, R. C. Jogos Computacionais na Educação Matemática. Revista de Educação ANEC, Brasília, v. 151, p. 103-112, 2009.

GRANDO, R. C. Recursos didáticos na Educação Matemática: jogos e materiais manipulativos. Revista Eletrônica Debates em Educação Científica e Tecnológica, v.05, p. 393-416, 2015.

HEIDEGGER, M. Conferências e escritos filosóficos. Tradução e notas Ernildo Stein. São Paulo: Nova Cultural, 1999. 
DOI: http://dx.doi.org/10.33238/ReBECEM.2019.v.3.n.1.21925

HEIDEGGER, M. Ser e Tempo. Tradução de Márcia de Sá Cavalcante. Petrópolis: Vozes, 2005.

KIRSCHNER, P. A. Do we need teachers as designers of technology enhanced learning? Instructional Science, Amsterdam, n. 43, p. 309-322, 2015.

KIRSCHNER, P. A., DE BRUYCKERE, P. The myths of the digital native and the multitasker. Teaching and Teacher Education, New York, n. 67, p. 135-142, 2017.

LÉVY, P. Cibercultura. Tradução Carlos Irineu da Costa. 2. ed. São Paulo: Editora 34, 1999.

MARQUES, A. C. C. O Projeto Um Computador por Aluno UCA: reações na escola, professores, alunos, institucional. 2009. Dissertação (Mestrado em Educação) - Faculdade de Educação, Universidade Federal do Paraná, Curitiba, 2009.

MERLEAU-PONTY, M. Fenomenologia da percepção. Tradução de Carlos Alberto Ribeiro de Moura. São Paulo: Martins Fontes, 2006.

NEGROPONTE, N. A vida digital. São Paulo: Companhia das Letras, 1995.

NOVAK, T. C. U. N.; PASSOS, A. M. A Utilização Do Origami No Ensino Da Geometria: Relatos De Uma Experiência. 2007. Disponível em:

<http://www.diaadiaeducacao.pr.gov.br/portals/pde/arquivos/719-4.pdf $>$. Acesso em: 12 fev. 2019.

ORLOVSKI, N.; KALINKE, M. A.; MOCROSKY, L. F. O Uso das Novas Tecnologias: um olhar para a formação do professor que ensina Matemática nos anos iniciais. Revista

Paranaense de Educação Matemática, Campo Mourão, v. 3, n. 4, p. 70-88, 2014.

PAPERT, S. A Família em Rede. Lisboa: Relógio D'água Editores, 1997.

PINHEIRO, J. M. L. O movimento e a percepção do movimento em ambientes de Geometria Dinâmica. 2018. Tese (Doutorado em Educação Matemática) - Instituto de Geociências e Ciências Exatas, Universidade Estadual Paulista, Rio Claro, 2018.

PRENSKY, M. Digital natives, digital immigrants. On the Horizon. NCB University Press, v. 9, n. 5, p. 1-6, 2001.

ROSA, M.; BICUDO, M. A. V. Focando a constituição do conhecimento matemático que se dá no trabalho pedagógico que desenvolve atividades com tecnologias digitais. In: PAULO, R. M.; FIRME, I. C.; BATISTA, C. C. (orgs.). Ser professor com tecnologias: sentidos e significados. São Paulo: Cultura Acadêmica Editora, 2018. p. 13- 44. ePUB.

ROWLANDS, I. et al. The Google generation: the information behaviour of the researcher of the future. 2008.

SALEN, K; ZIMMERMAN, E. Rules of play: Game Design Fundamentals. Cambridge, MA: MIT Press, 2003.

SANTAELLA, L. Navegar no ciberespaço: o perfil cognitivo do leitor imersivo. São Paulo: Paulus, 2004. 
DOI: http://dx.doi.org/10.33238/ReBECEM.2019.v.3.n.1.21925

SÃO PAULO. Matemática: ensino fundamental. Secretaria da Educação, Caderno do Professor $-9^{\circ}$ ano. São Paulo: SEE, v. 2, 2017.

SCHOENFELD, A. Por que toda esta agitação acerca da resolução de problemas? In: ABRANTES, P.; LEAL, L. C.; PONTE, J. P. (eds.). Investigar para aprender matemática. Lisboa: APM e Projecto MPT, 1996. p. 61-72.

TEZANI, T. C. R. Nativos Digitais: Considerações sobre os alunos contemporâneos e a possibilidade de se (re) pensar a prática pedagógica. Revista Brasileira de Psicologia e Educação, Araraquara, v. 19, n. 2, p. 295-307, jul./dez. 2017.

TONÉIS, Cristiano N. O design de Puzzles nos jogos digitais. SBC - Proceedings of SBGames 2016, São Paulo, p. 404-411, sept. 2016.

WENNER, M. The serious need for play. Scientific American Mind, v. 20, n. 1, p. 22-29, 2009.

Convidado em: 13 de dezembro de 2018 .

Submetido em: 14 de março de 2019.

Revisado em: 02 de maio de 2019. 